LHARES

CRUZADOS 


\section{Um País, Duas Pesquisas: A Construção dos Trabalhos de Campo no Marrocos}

\section{One Country, Two Researches: The Construction of Fieldwork in Morocco}

Bruno Ferraz Bartel

Programa de Pós-Graduação em Antropologia, Universidade Federal do Piauí, Teresina, Piauí, Brasil

\section{RESUMO}

O objetivo do artigo é demonstrar como as possibilidades de fazer pesquisas etnográficas no exterior durante a minha formação no Programa de Pós-Graduação em Antropologia da Universidade Federal Fluminense estão relacionadas ao contexto de internacionalização da pesquisa antropológica brasileira. Mais especificamente, procuro evidenciar como as dificuldades do campo, tais como a aprendizagem de uma nova língua, a adaptação a um novo contexto sociocultural e o estabelecimento de uma relação de confiança entre pesquisador e interlocutores para a realização de fotos e vídeos no campo etnográfico, podem ser superadas com o estabelecimento de rotinas e ajuda dos interlocutores e de outros pesquisadores.

Palavras-chave: Trabalho de campo, Internacionalização, Marrocos.

\section{ABSTRACT}

The article aims to demonstrate how possibilities of doing ethnographic research abroad during my training in the Graduate Program in Anthropology at Universidade Federal Fluminense are related to the context of internationalization of Brazilian anthropological research. More specifically, I try to show how the difficulties of the fieldwork, such as learning a new language, adapting to a new sociocultural context, and establishing arelationship of trust between researcher and interlocutors to take pictures and videos in the ethnographic field can be overcome with the establishment of routines and help from interlocutors and other researchers.

Keywords: Fieldwork, Internationalization, Morocco. 


\section{INTRODUÇÃO}

A realização de trabalhos etnográficos no exterior tem sido um dos desafios para a antropologia brasileira em seu afinco projeto de internacionalização (FRY, 2004). Docentes e discentes têm colaborado para ampliar as redes acadêmicas a partir de vínculos institucionais com grupos especializados (SCHUCH, 2018) ou por interesses pessoais (RIBEIRO, 2005).

O objetivo do artigo é demonstrar como as possibilidades de fazer pesquisas etnográficas no exterior durante a minha formação no Programa de Pós-Graduação em Antropologia da Universidade Federal Fluminense (PPGA/UFF) estão relacionadas a esse contexto de internacionalização da antropologia brasileira. Mais especificamente, procuro evidenciar como as dificuldades do campo, tais como a aprendizagem de uma nova língua, a adaptação a um novo contexto sociocultural e o estabelecimento de uma relação de confiança entre pesquisador e interlocutores para a realização de fotos e vídeos no campo etnográfico, podem ser superados com o estabelecimento de rotinas e ajuda dos interlocutores e de outros pesquisadores.

Apresento as experiências de pesquisa de campo no Marrocos adquiridas em dois diferentes momentos de minha formação acadêmica: no mestrado, em 2012 (10 meses), e, posteriormente, no doutorado, entre os anos de 2014 e 2017 (13 meses). Não pretendo elaborar os pormenores dessas "aventuras antropológicas" em termos de uma análise discursiva sobre o papel da escrita no fazer etnográfico (CLIFFORD, 1986) ou das práticas de análise cultural e de representação do outro (CRAPANZANO, 1980; RABINOW, 1977).

Desde já, faz-se necessário explicar que a opção pelo Marrocos contrasta com a maioria dos trabalhos de campo etnográficos realizados pelos discentes brasileiros no exterior. Segundo Fry (2004), a maior parte dos intercâmbios institucionais em Antropologia tem se concentrado em países da América Latina ou em regiões geográficas onde a língua portuguesa é predominante. A possibilidade de realizar a pesquisa no Marrocos esteve diretamente relacionada ao Núcleo de Estudos do Oriente Médio ${ }^{1}$ (NEOM), grupo de pesquisa no qual estou vinculado

1 O NEOM foi criado em 2003 no âmbito do PPGA/UFF pelos professores Dr. Paulo Gabriel Hilu da Rocha Pinto (PPGA, UFF), Dr. Paul Edouard Amar (Global Studies Department, University of California Santa Barbara) e Dra. Ella Shohat (Departments of Art \& Public Policy and Middle Eastern \& Islamic Studies, New York University). Atualmente é coordenado pelo professor Dr. Paulo Gabriel Hilu da Rocha Pinto, tendo como vice-coordenadora a professora Dra. Gisele Fonseca Chagas. O NEOM tem por objetivo criar uma estrutura acadêmica que possa atender à crescente demanda de informação e análises sobre temas ligados a esta região e às comunidades diaspóricas de populações originárias ou ligadas ao Oriente Médio. 
desde o mestrado. Os incentivos para a realização de pesquisas no exterior é uma das características dos coordenadores do NEOM que, desde o mestrado, estimulam seus pesquisadores a submeter projetos às agências de fomento que os possibilitem realizar o trabalho de campo em países do norte da África e do Oriente Médio. É essa diferenciação, em comparação às escolhas feitas pela maioria dos antropólogos brasileiros, que justifica a escolha em detalhar os desafios acadêmicos na constituição dessas etnografias, ou as "teorias vividas" (PEIRANO, 2008) neste artigo.

A partir dessa observação, passo a apresentação do texto, que está estruturado em dois eixos. No primeiro, demonstro os caminhos que me conduziriam ao Marrocos a fim de ressaltar como a possibilidade de fazer-pesquisa de campo naquele contexto não estava relacionado a uma escolha pessoal, mas aos vínculos institucionais estabelecidos pelo NEOM com redes acadêmicas interessadas em alargar os laços associativos com os países do Sul Global (cooperação Sul-Sul). Além disso, busco evidenciar que as dificuldades em relação ao trabalho de campo no exterior não começam quando desembarcamos no país de destino, mas ainda no Brasil, quando devemos conciliar os preparativos da viagem com as atividades do nosso cotidiano.

No segundo eixo, procuro me aprofundar nos elementos organizacionais e nos cotidianos religiosos investigados nos trabalhos de campo realizados no Marrocos com o objetivo de delinear as questões norteadoras das etnografias construídas durante a pós-graduação. Assim, a construção dos objetos das pesquisas de mestrado e doutorado não deixaram de problematizar as oportunidades criadas pelos institutos acadêmicos que me acolheram no Marrocos.

\section{DE PERTO E DE LONGE: 0 MARROCOS E A ANTROPOLOGIA}

O Marrocos contemporâneo é marcado pela diversidade étnica e religiosa, e conta com uma população estimada em 37 milhões de habitantes. Em termos de etnicidade, a população marroquina é composta, em sua maioria, por árabes (69.5\%) e berberes (29.6\%), além de imgrantes vindos dos demais países da África e da Europa, que totalizam um percentual de 0,9\%. No campo da religiosidade, sua população é predominantemente ligada ao Islã $\operatorname{sunita}^{2}(98.7 \%)$,

2 Os sunitas formam o maior ramo do Islã ( $85 \%$ dos muçulmanos) em comparação com os xiitas, que possuem apenas $15 \%$. Com a morte do Profeta, a questão de sua sucessão na liderança da comunidade muçulmana se colocou de maneira premente. Aqueles que evocavam apenas a tradição deixada por Mohammed (sunna), a qual segundo eles não incluiria as regras de sucessão, foram designados coletivamente como sunitas. 
além de conter uma minoria de judeus $(0,2 \%)$ e de cristãos $(1.1 \%)$.

A partir dos anos de 1960, o Marrocos passou a atrair o interesse de pesquisadores, sobretudo, na área da Antropologia da Religião. Algumas dessas pesquisas contribuíram para as análises sobre os modelos de poder, tomando por referência o relacionamento entre santidade e autoridade no sufismo - a via mística do Islã (CORNELL, 1998; GELLNER, 1969; HAMMOUDI, 1997). Outras se debruçaram sobre o desenvolvimento religioso a partir da experiência marroquina (GEERTZ, 1997, 2004), seja a partir da comparação com o judaísmo (ROSEN, 1972), seja a partir dos relacionamentos entre poder e produção de conhecimento (EICKELMAN, 1985). Não é possível, por exemplo, falar sobre a "virada hermenêutica" ou sobre a emergência do que viria a ser denominado "Antropologia Interpretativa", vinculadas à Antropologia Americana, nas décadas de 1960 e 1970, sem considerar as diversas incursões etnográficas realizadas no país.

Clifford Geertz (1926-2006) é o representante mais conhecido dessa abordagem antropológica. O Marrocos serviu de locus para várias de suas reflexões sobre a dinâmica religiosa observada no país (RACHIK, 2012). O Islã marroquino (GEERTZ, 2004), por exemplo, foi o resultado do projeto comparativo empreendido por Geertz, baseado nas formas de devoção aos santos no país em oposição ao que ele observou na Indonésia (GEERTZ, 1960). Cabe mencionar também os trabalhos que vieram a ser publicados pelos integrantes da equipe que o referido autor liderou no país entre os anos de 1965 e 1971, composta por sua esposa (GEERTZ et al., 1979); seus três alunos de doutorado da Universidade de Chicago (DICHTER, 2009; RABINOW, 1975, 1977; ROSEN, 1972, 1984); e de um fotógrafo profissional, Paul Hyman (SLYOMOVICS, 2009).

O Marrocos seguiu fazendo parte da trajetória de outros alunos de Geertz. Eickelman (1976), Brown (1976), Crapanzano (1973) e Dywer (1982) ampliaram a concepção semiótica de cultura proposta por seu mestre a partir do contexto marroquino. Crapanzano (1973), por exemplo, produziu uma etnografia sobre os sistemas terapêuticos de cura entre os adeptos sufis da Hamadsha amparado nos símbolos mobilizados nas arenas rituais. Ainda a título de exemplo, Rabinow (1975) tomou o caso de Sidi Lahcen para analisar o sistema de dominação simbólica presente na sociedade marroquina a partir dos cultos aos santos.

$\mathrm{O}$ contexto marroquino proporcionou novos experimentos relacionados à escrita etnográfica no campo (CRAPANZANO, 1980; DWYER, 1982; GEERTZ, 1995; RABINOW, 1977), o recurso da história como compreensão das mudanças sociais (BROWN, 1976), estudos sobre a construção das relações sociais nas comunidades muçulmanas (ROSEN, 1984) e análises envolvendo poder e religião, seja a partir da exibição de seus conflitos na esfera pública 
(MUNSON Jr., 1993) seja por intermédio das relações entre mestre e discípulo nas ordens sufis (HAMMOUDI, 1997). Para além disso, a obra de Geertz permitiu lançar um olhar sobre o país a partir da perspectiva dos próprios marroquinos que contestaram, a seu modo, as visões anteriormente desenvolvidas por pesquisadores europeus, especialmente franceses, sobre a dinâmica religiosa daquele contexto (EICKELMAN, 2009; RACHIK, 2012).

A apresentação desse quadro teórico não tem o objetivo de fazer uma síntese das pesquisas etnográficas elaboradas a partir do Marrocos, mas sinalizar ao leitor a vasta produção sobre os estudos antropológicos tomando a sociedade marroquina como locus de pesquisa. Embora as etnografias citadas sobre o Marrocos estivessem presentes nos programas das disciplinas cursadas sobre a religião islâmica ainda na graduação ${ }^{3}$ interrompida em Ciências Sociais (UFF) e, posteriormente, no ingresso ao PPGA (2011), nunca vislumbrei a possibilidade de fazer trabalho de campo no país.

A possibilidade de organizar uma viagem ao Marrocos me foi oferecida pela pesquisadora Dra. Silvia Montenegro da Universidade Nacional de Rosário (UNR, Argentina), a partir de um convite informal em julho de 2011. Nessa conversa, fui convidado a participar do primeiro convênio acadêmico estabelecido entre a Universidade Mohamed V (UM5-Agdal, Marrocos) e a UNR. Segundo ela, o acordo firmado entre as universidades propunha o envio de dois estudantes argentinos para o Marrocos, a partir de 2012. Porém, diante da ausência de um segundo nome para compor a equipe, a referida pesquisadora estendeu a oportunidade para outros membros estrangeiros associados ao seu grupo de pesquisa ${ }^{4}$.

Quando eu recebi o convite para o intercâmbio de pesquisa estabelecido pela $\mathrm{UNR}^{5}$, tive poucos meses para rever toda a bibliográfica teórico-metodológica referente ao Marrocos disponível para escrever o projeto de pesquisa e formalizá-lo, tanto no PPGA quanto na instituição marroquina que me acolheria. A primeira dificuldade foi conciliar a escrita do projeto de pesquisa com a finalização de três disciplinas que estavam em curso no programa e o trabalho

3 A minha formação inicial está ligada aos cursos de licenciatura (2001-2005) e bacharelado (2005-2006) em Geografia pela Universidade Federal Fluminense.

4 Coordenadora do Centro de Estudios de Diversidad Religiosa y Sociedad, localizado na cidade de Rosário, Argentina. O grupo possui como característica a organização de um espaço plural de encontro e interação entre religiosos e acadêmicos com destaque para o estudo sobre os processos migratórios.

5 A confirmação da viagem veio somente em 20 de dezembro de 2011. Defendi meu projeto de mestrado no PPGA no dia 10 de janeiro de 2012. Embarquei para o Marrocos três dias depois. Entre 15 de janeiro a 15 junho de 2012, a equipe seria formada basicamente por Lucía Salinas (doutoranda em Antropologia da UNR) e por mim (mestrando em Antropologia da UFF). Lucía retornaria após os seis meses de convênio. Quanto a mim, após estabelecer residência na capital (Rabat), decidi prolongar a minha estadia por mais quatro meses no Marrocos a fim de contemplar, ao máximo, a duração do trabalho de campo no exterior. 
como professor de ensino médio da rede pública, além da burocracia que eu desconhecia para o pedido de afastamento das minhas funções na Secretaria de Estado de Educação do Rio de Janeiro (SEEDUC).

Até o final de 2011, o projeto de pesquisa de mestrado estava direcionado às relações de ambivalência entre gênios (jinns ${ }^{\wp}$ ) e humanos na promoção de um imaginário religioso comum ao Islã. Meu objetivo, naquela época, era analisar as percepções dos muçulmanos sunitas da Sociedade Beneficente Muçulmana do Rio de Janeiro (SBMRJ) sobre essa relação.

A partir de um trabalho sobre a ação dos jinns apresentado na IX Reunião de Antropologia do Mercosul7 $^{7}$, no grupo de trabalho coordenado pela professora Silvia Montenegro da UNR, e do meu então orientador, professor Paulo Gabriel Hilu da Rocha Pinto, surgiu a oportunidade de uma bolsa de pesquisa oferecida pela Agência Marroquina de Cooperação Internacional (AMCI). Essa situação me permitiria repensar a problemática dos jinns num contexto cultural distinto da SBMRJ.

A bolsa de pesquisa estava vinculada ao Instituto de Estudos Hispano-Lusófonos (IEHL ${ }^{8}$ ) - centro acadêmico ligado à UM5-Agdal e localizado na cidade de Rabat (capital do Marrocos). Atuar como pesquisador associado ao IEHL foi fundamental para que eu pudesse desenvolver o projeto de pesquisa quando cheguei ao país. Mesmo com as leituras mais cuidadosas sobre a dinâmica religiosa marroquina, estar em um país complemente distinto do meu horizonte cultural, revelou-se profundamente desafiador do ponto de vista pessoal e profissional. Nesse sentido, a convivência acadêmica com pesquisadores e funcionários do IEHL era intensamente estimulante do ponto de vista da pesquisa. Essa convivência levou-me a expandir a pesquisa etnográfica a fim de que eu contemplasse a temática dos jinns, mas que a pudesse desenvolvê-la em um universo empírico em que a sua centralidade fosse dominante.

Essa experiência resultou na dissertação A ambiguidade do sagrado: o culto a Aisha Qandisha na vila de Sidi 'Ali, Marrocos, defendida em setembro de 2013 e publicada em livro

6 Os jinns são seres invisíveis feitos de fogo que compõem o universo simbólico da religião islâmica. O termo jnun indica o seu plural no Marrocos e nos demais países que possuem o Islã como código e discurso cultural. Um ser feminino deste tipo recebe, às vezes, a denominação de jinniya. Acrescentarei um "s" no final dos termos em árabe para indicar o seu plural. A transcrição das palavras árabes foi feita por meio da versão simplificada do sistema de transliteração contida no periódico International Journal of Middle East Studies (IJMES). O termo Hamdouchiya é o único que foge a essa regra devido ao próprio uso dado pelos interlocutores na transliteração francesa dessa palavra.

7 Disponível em: https://doczz.com.br/doc/172141/a-cren\%C3\%A7a-em-jinns-na-comunidade-mu\%C3\%A7ulmana-sunita-do. Acesso em: 31 mar. 2021.

8 O IEHL se dedica aos estudos literários (línguas portuguesa e espanhola), mas também a produção de debates sobre crenças e práticas rituais islâmicas durante os períodos de ocupação francesa no Norte da África (Marrocos, Argélia e Tunísia) e de experiência pós-colonial. 
em 2016. A escolha da referida vila rural, que não estava contemplada inicialmente no projeto, aconteceu em decorrência das redes pessoais estabelecidas pela diretora do IEHL. Passei a fazer visitas frequentes a Sidi 'Ali' (província de Merhasiyne), localizada na região de Meknes-Fez, com o intuito de analisar o culto de um jinn feminino (Aisha Qandisha) presente no local. De volta ao Brasil, escrevi a dissertação demonstrando as condições e os elementos requeridos na construção de um sistema de comunicação ritual sob o aspecto de peregrinações, oferendas e sacrifícios de animais, além de rituais de transe e possessão, relacionados à figura desse agente religioso. A busca dos jinns pelos interlocutores tinha como objetivo a concretização de seus desejos e ambições em situações de crise de vida, assim como de solucionar seus conflitos e infortúnios pessoais. A obtenção de um emprego, a realização de um casamento, a geração de filhos ou, simplesmente, a cura de alguma doença são acontecimentos que faziam parte das temáticas privilegiadas, principalmente por mulheres, no cotidiano da vida religiosa em Sidi 'Ali (BARTEL, 2013; 2016b).

A escrita da dissertação foi limitada não só pelo objeto de pesquisa, mas também pelos prazos acadêmicos. Ainda possuía em mãos um vasto material de campo que se desdobrou em artigos e na viabilidade de novos projetos de pesquisa.

Em janeiro de 2015, já no curso de doutorado no PPGA/UFF, retornei ao Marrocos para realizar um trabalho de campo exploratório de um mês. A viagem teve como finalidade a retomada de alguns contatos, o estabelecimento de outros e a melhor delimitação do tema correspondente ao universo do sufismo marroquino que seria desenvolvido no doutorado. Inicialmente, meu interesse voltava-se para a mobilização do poder divino (baraka) pelos descendentes de Sidi 'Ali ben Hamdouche (1666-1722) na construção das peregrinações (ziyaras) pelos adeptos e devotos do santo junto ao seu mausoléu (BARTEL, 2016a). Depois dessa curta iniciativa, optei por me concentrar sobre os mecanismos disciplinares presentes nos locais de culto da confraria ${ }^{10}$ sufi Hamdouchiya, responsáveis pela produção das virtudes religiosas entre os participantes desta comunidade sufi (BARTEL, 2019).

Cabe ressaltar que o meu interesse pela Hamdouchiya estava relacionado aos contatos estabelecidos entre os membros dessa comunidade sufi durante a pesquisa no mestrado e, que, foi recuperada no retorno ao país. A convivência com alguns descendentes do santo (shari-

9 A etnografia de Crapanzano (1973) teve como base esse local.

$10 \mathrm{O}$ termo compreende tanto o processo iniciático individual por um caminho ou via mística (tariqa) quanto a forma organizacional religiosa (filiação) constituída por meio de uma tradição que tem como base a vida e obra de um santo patrono. Nessa perspectiva, a tariqa é vista como um caminho de santidade, um caminho "vertical" que une o discípulo ao mestre (ao santo, como descrevo na tese) e, além disso, ao Profeta. 
$f_{S^{11}}$ ) em Sidi 'Ali durante 2012 e demais discípulos (murids) da zawiya ${ }^{12}$, em Rabat, em 2015, permitiu-me perceber as diferenças existentes entre os padrões de produção das experiências místicas, sem perder de vista o modus operandi dessas práticas na vida cotidiana das zawiyas. A ampliação posterior do número de interlocutores favoreceu a compreensão das variadas experiências religiosas mobilizadas pelas formas devocionais da Hamdouchiya.

A bolsa de Doutorado-Sanduíche da Fundação de Amparo à Pesquisa do Estado do Rio de Janeiro (FAPERJ), que obtive no final do primeiro semestre de 2016, possibilitou o meu retorno ao Marrocos e o estabelecimento do vínculo acadêmico com o Centre Jacques Berque ${ }^{13}$ (CJB) - centro de referência na área das Ciências Sociais da França sobre o norte da África, localizado em Rabat. O financiamento proporcionou o auxílio financeiro imprescindível para os deslocamentos e as estadias entre os locais de culto que compuseram o universo empírico da pesquisa. Para o início do trabalho de campo em outubro de 2016, optei por regressar à vila de Sidi 'Ali, como um meio de reestabelecer os meus contatos feitos em 2012 e 2015 com os descendentes do santo local e de iniciar, brevemente, um mapeamento das suas redes de alianças com os outros discípulos. Nesse sentido, as indicações das pessoas relacionadas com os locais de culto da Hamdouchiya foram fornecidas tanto por intermédio dos laços de afinidade e amizade (cidades de Fez, Safi e Essaouira) quanto por relações de parentesco consanguíneo (cidades de Rabat e Taroudant) dos descendentes.

Essa segunda experiência no Marrocos transformou-se na tese Criações devocionais no sufismo marroquino: performance e ritual entre os discípulos da tariqa Hamdouchiya, defendida em fevereiro de 2019, na qual analiso as condições e os elementos que promoviam a incorporação de subjetividades - conjunto de modos de percepção, afeto, pensamento, desejo, medo e assim por diante - por meio das interações, participações rituais e produções performativas dos

11 A monarquia Alauita, desde a independência do país em 1956, auxilia com uma quantia financeira, todos os anos, as famílias que possuem uma genealogia com a do Profeta. A palavra shurfa no Marrocos é o plural do termo sharif e serve para denominar todos os indivíduos que participam da mesma narrativa mítica de linhagem ou de descendência direta com a família do Profeta.

12 O termo significa "canto" em árabe. É usado para designar o edifício que serve como centro ritual para a comunidade sufi. Também pode ser usado em referência à própria comunidade.

13 O CJB caracteriza-se por ser um centro acadêmico francês subsidiado pelo Centro Nacional de Pesquisa Científica (CNRS) e que conta com uma ampla rede de pesquisadores europeus reunidos em múltiplos campos disciplinares (Antropologia, Sociologia, Ciências Políticas, Geografia, História, Etnomusicologia, Arquitetura, Direito e Economia) sobre a sociedade marroquina, sendo muitos deles voltados principalmente para a temática da diversidade religiosa e histórico-cultural do país. Meus contatos com os diretores do centro aconteceram em dois momentos: primeiro durante a pesquisa de mestrado em 2012 com o pesquisador Dr. Baudouin Dupret (2012-2015) e no meu retorno, em janeiro de 2015; e depois com a pesquisadora Dra. Sabrina Mervin (2015-2017), durante a participação dela numa série de seminários organizados pelo PPGA/UFF, a convite do NEOM, em 2013. 
discípulos da comunidade sufi Hamdouchiya. Circular por essas redes me fez perceber como o regime disciplinar baseado em técnicas sufis - invocações dos nomes e da presença de Deus (dhikrs), recitações dos poemas relativos ao santo patrono (qasidas) e sessões rituais - reorganizavam as subjetividades discursivas e criavam um tipo de sujeito religioso no Marrocos.

\section{AS EXPERIÊNCIAS NUM PAÍS ISLÂMICO: CONDIÇ̃̃ES DAS PESQUISAS E RESPECTIVOS DESAFIOS}

O relato das experiências que busco apresentar é uma tentativa de explorar os desafios do trabalho de campo no exterior. Algumas delas são comuns a outros pesquisadores, outras são referentes ao contexto marroquino. A seguir, demonstro, a partir de três pontos como os obstáculos se fizeram presentes em toda a minha trajetória e como a superação deles fez parte das produções do fazer etnográfico.

Durante o mestrado, eu acompanhava as pessoas, com a sua devida autorização, às visitações à gruta de Aisha Qandisha. Eu aproveitava essas ocasiões para observar dois aspectos presentes nas visitações. Em primeiro lugar, as trocas simbólicas representadas pelas oferendas de elementos (vegetais e minerais) na forma de um prato de palha ( $t^{\prime} b a g$ ) envolvido por um tecido (shad), cuja cor variava em função dos dias da semana ou das preferências dos jinns. Parte desse material era entregue aos responsáveis da gruta como forma de pagamento pela utilização de seu espaço; a outra parte era lançada no muro construído dentro da gruta, destinado à destruição dos objetos (velas, perfumes e incensos) através do fogo, além de servir como espaço para libações e entrega de objetos investidos de poder divino. Em segundo lugar, o foco recaía sobre o simbolismo contido no sangue dos sacrifícios de animais (galos, galinhas, bodes, cabras, carneiros e ovelhas), imolados em um espaço no interior da gruta.

Paralelamente, eu frequentava, com a devida autorização, as residências alugadas pelos peregrinos ou emprestadas a eles para a realização de rituais de transe e possessão nos dias de peregrinação em Sidi 'Ali, denominadas lilas. Buscava entender as causas atribuídas à Aisha Qandisha na produção dos estados corporais apresentados pelos indivíduos, principalmente, pelas mulheres.

A maior parte da pesquisa foi conduzida em francês, tanto as entrevistas quanto as conversas informais com os interlocutores durante o trabalho de campo. $\mathrm{Na}$ ocasião, ainda 
me faltava o domínio do árabe coloquial marroquino, denominado darija. Ainda no Brasil, quando me interessei pelos estudos sobre o Islã, passei a ter aulas de árabe na SBMRJ. No entanto, essas aulas pouco me ajudaram no trabalho de campo, visto que o árabe literário clássico (modern standard arabic), tal como ensinado na SBMRJ, não era comum nas interações do dia a dia marroquino. Somente depois de dois meses instalado no país que eu comecei a me expressar minimamente em darija, depois de frequentar aulas particulares numa escola voltada para estrangeiros. Nos anos que se seguiram, pude ampliar meu domínio da variante da língua árabe falada no Marrocos, especialmente no desenvolvimento da leitura, já que eu ainda possuía dificuldade para manter longas conversas no idioma. Ainda assim, as dificuldades foram compensadas com a ajuda dos interlocutores e dos investigadores do IEHL, com quem eu me encontrava semanalmente. Entender o árabe marroquino era importante para precisar o vocabulário presentes nas tradições textuais e doutrinárias e, também, nos rituais.

Em algumas situações, a comunicação foi feita em espanhol. Isso aconteceu somente com os marroquinos que moravam no norte do país, já que o protetorado espanhol difundiu o aprendizado da língua espanhola. Em outros momentos, o inglês pode ser utilizado, mas só com as pessoas que possuíam contatos mais próximos com turistas, o que tem crescido nas últimas décadas.

Ter a possibilidade de me expressar em várias línguas, ajudou-me a ampliar as possibilidades de interação. Isso significava não apenas a busca por equivalentes referentes ao meu contexto cultural, mas também a presença de mecanismos de "distinção" entre alguns interlocutores. O uso do francês e espanhol remonta ao período colonial (1912-1956) e indica, ainda hoje, a forte influência delas no processo educacional de alguns interlocutores. Cabe mencionar que a língua francesa, em diversas situações de interação, continuava a ser vista como um símbolo da herança colonial, mesmo quando ela contribuía para uma gama de oportunidades às novas gerações, exigidas no mercado de trabalho marroquino. Já a língua inglesa se fazia mais presente entre os interlocutores jovens ( 15 a 29 anos) devido a influência recente dos EUA sobre o Marrocos, orientado pela política cultural de Mohammed VI (1999-atual).

Em fevereiro de 2012, ainda nos primeiros meses da minha chegada ao país, a diretora do IEHL intermediou a minha visita à vila de Sidi 'Ali, durante o período de celebração do nascimento do profeta Mohammed (Mawlid an-Nabi), em Sidi 'Ali. Esse passo foi decisivo para a escolha dessa vila como lócus da pesquisa etnográfica. A rotina de visitas estabelecida a partir desse momento determinou o rumo da pesquisa. Geralmente, eu permanecia entre dois a quatro dias na vila, num quarto oferecido pelo proprietário do hotel Marhaba. O hotel era a principal fonte de renda desse membro da Hamdouchiya, bastante conhecido nos arredores da 
vila. Os peregrinos escolhiam esse local, dentre as poucas opções existentes na vila, também devido a sua proximidade com os outros pontos de visitação, como o mausoléu de Sidi 'Ali ben Hamdouche, a gruta de Aisha Qandisha e a fonte de água utilizada para a purificação corporal ('Ayn Kabir). Dispor de um quarto somente para mim ajudava na hora de organizar as notas do trabalho de campo e eu também podia receber a visita de pessoas interessadas na minha pesquisa que acabaram se tornando, com o tempo, interlocutores; tais como moradores locais, funcionários das lojas de artigos religiosos e, até mesmo, alguns membros da Hamdouchiya. As conversas regadas a "uísque marroquino", nome dado pelos marroquinos ao chá com menta (aytay bi-nana), contribuíram para a criação de um ambiente de sociabilidade.

Fazer parte do cotidiano dos interlocutores estreitou as relações de confiança, que são fundamentais para qualquer etnografia, permitindo assim o contato com demais moradores locais. Além de favorecer um convívio mais próximo com os visitantes, estar no hotel me colocava em contato com os peregrinos. Em conversas estabelecidas nas áreas de convivência, eu podia questioná-los sobre as razões que os levavam a visitar a vila de Sidi 'Ali e sobre as representações que eles faziam da figura e da personalidade de Aisha Qandisha.

A maioria dos visitantes da vila era composta por mulheres, geralmente acompanhadas por parentes e amigas, formando grupos de três a oito pessoas. Registrei apenas dois casais visitando a vila durante o campo. Em outras situações, o que era mais comum, podia-se verificar casais acompanhando grupos de mulheres, mas nunca grupos de casais visitando a vila de Sidi 'Ali. Após o primeiro contato com os peregrinos que estavam hospedados no hotel, eu pedia-lhes a autorização para acompanhá-los nas visitações aos locais considerados sagrados. Após o estabelecimento de um certo grau de confiança, as conversas me renderam alguns convites para reencontros fora dos limites da vila.

Em algumas ocasiões, eu frequentei as residências dos peregrinos que visitavam a vila de Sidi 'Ali oriundos das cidades de Casablanca, Rabat e Meknes, o que serviu para complementar as minhas análises sobre a intervenção dos jinns na realidade dessas pessoas e, mais especificamente, sobre o papel desenvolvido por Aisha Qandisha na constituição das experiências religiosas que determinados indivíduos almejavam. Com os casais, os convites geralmente partiam dos homens, que organizavam almoços nos quais me apresentavam aos demais membros da família. Esses momentos de confraternização eram importantes para entender como os demais familiares refletiam a respeito da agência dos jinns. Já os convites feitos pelas mulheres eram sempre feitos pela mais velha, o que também acontecia na forma de um evento domiciliar (almoço ou jantar), servindo para ampliar o número de interlocutores e, consequentemente, proporcionando-me novas interpretações sobre a intervenção dos jinns no cotidiano das pessoas. 
Preservei os nomes dos interlocutores a partir de suas substituições por outros. A idade, estado civil, ocupação e residência dos interlocutores eram informações que acompanhavam o nome fictício na etnografia, o que eu julgava ser um meio de sinalizar para o leitor a multiplicidade de pessoas, com diferentes trajetórias, que buscavam os jinns. Algumas das entrevistas foram registradas com o uso de um gravador digital ou por intermédio de anotações em um caderno que me acompanhava, sempre que possível. Para as conversas de caráter informal, eu recorria à minha própria memória para registrar os pontos que julgava adequados para a pesquisa. Muitas vezes eram as próprias pessoas que anotavam para mim, num pedaço de papel ou num guardanapo, o que consideravam significativo sobre um tema específico suscitado por mim.

O mesmo aconteceu com os proprietários das lojas de artigos religiosos na vila de Sidi 'Ali, durante as minhas estadias. Após o estabelecimento de uma rotina na vila, eu pude frequentar algumas lojas na tentativa de investigar os símbolos associados aos objetos ofertados a Aisha Qandisha e que eram comprados pelos peregrinos. Nesses locais, eu ia me familiarizando com diversos temas (magia, presságios, práticas divinatórias, sonhos), que num primeiro momento não fariam parte do universo da minha pesquisa etnográfica, mas que, vez ou outra, acabavam se cruzando ou se conectando de alguma forma com a temática dos jinns. Cada ida às lojas proporcionava ampliar os elementos a serem considerados na pesquisa.

Nas lojas, eu aprendia que cada objeto expressava símbolos demandados pelos indivíduos que visitavam a gruta de Aisha Qandisha, materializando assim as suas expectativas na construção de uma experiência religiosa. Foi a partir desse mercado religioso que me familiarizei com a dinâmica dos rituais que aconteciam na gruta, em que as pessoas buscavam a intervenção de Aisha Qandisha em suas vidas. Ademais, foi através dos comerciantes que pude saber em quais locais seriam organizados os rituais noturnos (lilas), nos finais de semana. Por intermédio deles ou de seus clientes, eu pude frequentar e observar esses rituais na expectativa de compreender o fenômeno do transe e da possessão envolvendo a agência de Aisha Qandisha.

O uso de câmeras fotográficas ou filmadoras para o registro das experiências religiosas em Sidi 'Ali era proibido; o que não quer dizer que isso não pudesse ser negociado. O grupo que controlava a gruta de Aisha Qandisha era completamente contra qualquer tipo de registro sobre o que acontecia dentro de seus limites. Alguns diziam que faziam isso para proteger as tradições antigas vinculadas à figura de Aisha Qandisha no país; outros diziam que queriam evitar a exposição dos rituais ocorridos na gruta, representados como "exóticos" após a veiculação de uma reportagem editada por dois jornalistas franceses em 2007, sobre os sacrifícios de animais destinados ao culto de Aisha Qandisha.

Nos rituais de transe e possessão realizados fora do espaço da gruta de Aisha Qandisha, 
as imagens e vídeos podiam ser captados sem maiores problemas, ou seja, quando eles eram abertos ao público (hadra), justamente porque muitos peregrinos também registravam esses momentos, especialmente os que envolviam as performances de flagelação corporal entre os adeptos sufis da Hamadsha. Ao longo da construção do trabalho de campo, pude registrar quatro sessões rituais (hadras), em distintos espaços na vila de Sidi 'Ali.

Nos rituais noturnos (lilas), organizados em espaços privados (casas ou hotéis) e geralmente alugados pelos peregrinos, eu procurava negociar a autorização para a produção de fotos e vídeos com o responsável pela organização do evento. Também era possível ver muitas pessoas realizando fotos e vídeos nessas ocasiões, por interesses diversos. Num universo de oito lilas observadas ao longo de minha pesquisa etnográfica em Sidi 'Ali, em apenas uma me foi negado o direito de registrar fotos ou vídeos.

Já na pesquisa de doutorado, o universo etnográfico contemplou as atividades rituais (dhikrs, qasidas e hadras) vivenciadas nos locais de culto, organizados pelo menos uma vez na semana e preparadas ocasionalmente entre os seis locais de culto da Hamdouchiya selecionados para a pesquisa. Embora tivesse acesso aos seis locais, o foco permaneceu sobre a zawiya Hamdouchiya localizada na cidade de Safi. A opção decorreu não somente pelo aprofundamento das minhas interações com os discípulos de Safi em relação aos demais adeptos da Hamdouchiya, mas, sobretudo, pelo acompanhamento de um ciclo de atividades realizadas por eles durante o trabalho de campo.

Após cinco meses de trabalho de campo nos locais de culto da Hamdouchiya, esbocei uma rotina de pesquisa com vistas à organização dos dados etnográficos segundo dois itinerários: o primeiro contemplou as visitas ao mausoléu de Sidi 'Ali e à comunidade religiosa ( ta $^{\prime}$ f $^{14}{ }^{14}$ ) de Fez e o segundo se concentrou sobre o eixo das zawiyas de Safi e Essaouira. Os dados sobre as zawiyas de Rabat e Taroudant se restringiram às celebrações do nascimento do Profeta (Mawlid an-Nabi), em dezembro de 2016, ou aos momentos de festividades, com os mesmos propósitos celebrativos, entre outros locais de culto da Hamdouchiya, em maio de 2017.

As visitas a Sidi 'Ali ocorriam às quintas e sextas-feiras, ao passo que as idas a Fez aconteciam aos sábados e domingos, por causa da grande quantidade de festivais de música sufi realizados pela ta 'ifa na região. Em Safi aconteciam todas às quintas-feiras, logo após a oração da tarde (salat al-asr), em que eram organizadas as leituras de alguns capítulos do Alcorão ${ }^{15}$

$14 \mathrm{O}$ termo compreende um grupo de discípulos reunidos em torno de uma liderança, estabelecidos fora dos limites físicos de uma zawiya.

15 O Alcorão é o resultado textual da recitação da palavra divina por Mohammed entre os anos de 610 e 632. 
(suras) e de trechos do livro "Dala'il al-Khayrat ${ }^{16 "}$ de Imam al-Jazouli entre os discípulos. Nas sextas-feiras, após a realização dessa mesma oração na zawiya, eu acompanhava as invocações dos nomes e da presença de Deus (dhikr), as recitações dos poemas (qasidas) vinculadas ao santo patrono e as sessões rituais (hadras), que incluem os ritmos musicais dos discípulos. Já em Essaouira, as práticas devocionais (qasidas e hadras) eram realizadas sempre aos domingos.

Além disso, era possível observar que alguns membros locais participavam de festividades ligadas à música sufi ou outras celebrações artísticas ocorridas na cidade. Para os demais dias da semana, longe desses dois itinerários - Sidi 'Ali-Fez e Safi-Essaouira -, eu me dedicava ora à rotina acadêmica do $\mathrm{CJB}$, ora à produção de entrevistas e conversas com os adeptos da zawiya de Rabat, devido à ausência de atividades religiosas nesse local ao longo do trabalho de campo, com exceção dos eventos ocorridos em dezembro de 2016.

Ao longo dos três primeiros meses do trabalho de campo, cabe apontar que a aceitação de minha pesquisa entre os discípulos foi estabelecida, muitas vezes, graças aos contatos diretos com alguns descendentes de Sidi 'Ali. A relação entre descendentes do santo e discípulos da Hamdouchiya era estabelecida periodicamente por meio de convites pessoais para participar das zawiyas e das peregrinações ao mausoléu de Sidi 'Ali ben Hamdouche.

Quando faço referência aos contatos prévios de determinados descendentes do santo com alguns discípulos para intermediar minha entrada nos locais de culto, não almejo conferir a isso uma demarcação de livre acesso ao cotidiano religioso desses últimos. Pelo contrário, as comunicações com esses membros, selecionados previamente, circunscreveram momentaneamente as interações locais com base em suas próprias redes pessoais. Foi somente após algum tempo de convivência (geralmente três meses) que outras redes, nesses mesmos locais de culto, se tornaram acessíveis. Mesmo assim, tal situação não determinava a totalidade das relações entre os discípulos.

As entrevistas foram mais frequentes no início da pesquisa, uma vez que as familiaridades com os interlocutores requisitaram mais tempo devido às formas de "sociação" (SIMMEL, 1983) manifestas na dimensão interacional. No tocante às conversas, destaco que elas constituíram uma forma fundamental de interação com os interlocutores, o que me ajudava na confrontação dos discursos oficiais sobre o Islã marroquino, referentes aos valores de moderação e tolerância, com as experiências diárias dos sujeitos.

Nesses momentos, minha familiaridade com a religião islâmica e, mais especificamente,

16 Escritos por Mohammed Sulaiman al-Jazouli (m.1465), ou simplesmente, Imam al-Jazouli, este livro pode ser caracterizado como um manual devocional devido à coleção de orações relacionadas ao Profeta. 
com o sufismo e o culto aos santos do Marrocos desde 2012, ficava evidente para os interlocutores. Isso se devia especialmente à formulação de perguntas nas entrevistas com vocabulário correspondente aos valores/atitudes requeridos durante a realização da pesquisa. Já para as conversas, destaco que as interações foram permeadas por conhecimentos envolvendo o tipo de Islã vinculado ao país e demais assuntos da sociedade marroquina, com o uso de provérbios populares, histórias pessoais e jocosidades dos interlocutores.

Minha entrada nos locais de culto, intermediada pelos descendentes do santo, estabeleceu para mim a "identidade de pesquisador da Hamdouchiya", muito embora o título não tenha impedido as intenções dos discípulos em me converterem, sobretudo, nos primeiros meses de campos. Ademais, a curiosidade acerca do pesquisador brasileiro que se esforçava para se comunicar em árabe facilitou, em diversas situações, a construção das interações com os interlocutores.

A produção de fotos e vídeos foi possível devido à autorização prévia dos discípulos de cada local de culto. Esses registros foram importantes não somente para auxiliar as descrições das atividades rituais desenvolvidas, mas também para o mapeamento das redes de afinidades entre os discípulos da Hamdouchiya no país, seja no cotidiano, seja durante algum evento específico. Nunca tive problemas com os membros de Sidi 'Ali, Fez, Rabat e Taroudant para realizar filmagens durante a pesquisa. Em Safi, eu era considerado o "fotógrafo oficial ${ }^{17}$ " da zawiya Hamdouchiya local, devido à qualidade das imagens e vídeos produzidos por meu celular, o que possibilitou diversas trocas de imagens e vídeos antigos com os adeptos locais, além de contribuir para a organização de um arquivo audiovisual realizado por alguns deles desde a década de 1980.

No entanto, tive algumas resistências por parte de dois discípulos da zawiya de Essaouira, durante o primeiro mês de trabalho de campo. A possibilidade de encontrar meus registros disponibilizados na Internet ou nas redes sociais os preocupava. $\mathrm{O}$ fato de um deles ser policial da guarda local e o outro ser estivador do porto - concorreu para essa preocupação, já que ambos queriam preservar as suas imagens públicas.

Para dar conta de tal desconforto, pedi a palavra depois de uma sessão ritual e assegurei publicamente a todos que os registros (fotos e vídeos) fariam parte somente da pesquisa e de que eles estariam disponibilizados por mim somente por meio de DVDs entre os adeptos de Essaouira. Os dois sujeitos ficaram satisfeitos com meu compromisso. Essa ação contou com a

17 Entre os interlocutores da Hamdouchiya de Safi eu era conhecido como "Rachid". Devo esse nome a um deles que decidiu me nomear assim desde que me conheceu no início do meu trabalho de campo, sendo aceito pelos demais. 
mediação de um outro interlocutor que me conheceu em um evento organizado pela zawiya de Taroudant. Ele reforçou minha posição de "fotógrafo oficial" da zawiya de Safi, o que significou minha reinserção em Essaouira como alguém comprometido, de alguma maneira, com os membros da Hamdouchiya e não como uma pessoa disposta a estabelecer relações conflitivas.

\section{PALAVRAS FINAIS}

A apresentação das experiências etnográficas realizadas no Marrocos, em períodos distintos, permitiu-me apontar três problemáticas fundamentais na construção do trabalho de campo no exterior ao longo da minha trajetória acadêmica a partir do NEOM (PPGA/UFF). Em primeiro lugar, destaco o aprendizado de uma nova língua (modern standard arabic/darija) para a negociação das interações no dia a dia relacionadas ao fazer etnográfico. Desde os ensinamentos clássicos de Bronislaw Malinowski (1884-1942) sobre a importância de se "dominar a língua nativa", algumas transformações nos contextos de produção do trabalho de campo são importantes e impactam as condições das empreitadas antropológicas contemporâneas.

Diferentes dos meus colegas doutorandos de CJB vindos da Europa (França, Alemanha e Itália), não pude contar com uma estrutura acadêmica que disponibilizasse cursos de conversação ${ }^{18} \mathrm{em}$ língua árabe previamente para a ida ao Marrocos. Foi somente quando estava em campo é que eu pude começar a aprender o árabe falado no país.

Em segundo, ao estabelecimento de uma ampla rede de contatos, seja pelas vias institucionais seja por meios pessoais, que permitiu o meu conhecimento da diversidade cultural no país. O IEHL e os descendentes de Sidi 'Ali ben Hamdouche foram vitais na construção dos contatos interacionais no mestrado e, sobretudo, para a ampliação da rede de interlocutores no doutorado. Uma das consequências disso, por exemplo, foi o mapeamento da quantidade de zawiyas ligadas à Hamdouchiya no país (32) e do sistema de alianças e afinidades existentes entre elas (BARTEL, 2019).

Neste sentido, os descendentes do santo me possibilitaram, num curto tempo, selecionar quais seriam os locais relevantes a serem contemplados na pesquisa. Mesmo que alguns

18 A opção dos pesquisadores do NEOM que tiveram a oportunidade de realizar seus trabalhos de campo no exterior têm sido recorrer às disciplinas dos cursos de graduação em Português-Árabe da Faculdade de Letras na Universidade Federal do Rio de Janeiro (UFRJ) ou aos cursos introdutórios organizados por entidades religiosas na cidade do Rio de Janeiro (igrejas maronitas ou mesquitas) ou, ainda, às aulas particulares. 
anos já tenham se passado, desde o final do trabalho de campo e da defesa de doutorado, alguns interlocutores mantêm contato comigo via redes sociais (Facebook e WhatsApp). De tempos em tempos, perguntas sobre o meu possível retorno ao Marrocos e a realização de uma comparação envolvendo as dinâmicas religiosas de outras zawiyas da Hamdouchiya, especialmente localizadas no norte do país, são frequentes.

Destaco ainda o papel da organização de estratégias de observação direta como parte de uma rotina no trabalho de campo. Reconheço o papel que o hotel Marhaba teve como um local expressivo no mestrado para desenvolver a interação com os peregrinos na vila de Sidi 'Ali, especialmente durante os finais de semana na realização dos rituais de seu interesse. Já no doutorado, foi necessário ressaltar que o tempo disponibilizado pelos membros da Hamdouchiya variava de acordo com o tipo de ocupação e/ou estilo de vida de cada um deles. A maioria dos adeptos da Hamdouchiya frequentava os locais de culto para praticarem as performances rituais pelo menos uma ou duas vezes por semana.

No trabalho de campo durante o doutorado tentei ainda interagir com os interlocutores nas esferas de sua vida social, como trabalho, família e lazer, o que somente foi possível à medida que as minhas interações com eles se tornavam mais frequentes. A ida a seus locais de trabalho e os convites para visitar ou, até mesmo, pernoitar em suas casas, onde moravam com suas famílias, indicavam a possibilidade, especialmente em Sidi 'Ali e em Safi, de observar no cotidiano a colocação em prática dos valores/atitudes sufis atribuídos pelos interlocutores.

Novamente, ressalto a importância do IEHL e do CJB como locais relevantes para a consolidação de uma grade de atividades a serem cumpridas como pesquisador associado. Ambos foram fundamentais para medir e avaliar a viabilidade das abordagens teórico-metodológicas adotadas no trabalho de campo por intermédio das discussões com os pesquisadores em seminários, palestras ou em conversas informais.

E, por último, sublinho as questões envolvendo os dilemas na produção dos registros audiovisuais. Fotos e vídeos formaram recursos valiosos nas remontagens das ações rituais pertinentes às pesquisas, especialmente diante da impossibilidade de registrar os acontecimentos em um bloco de notas (impresso/digital) ou advindas das falhas de memória, após o acompanhamento de rituais com longos períodos de duração, entrevistas ou conversas com os interlocutores. Seja a partir de situações restritivas ocorridas em 2012, como a vigilância das imagens na gruta de Aisha Qandisha, seja a partir de contextos mais fluídos em 2016/2017, como "fotógrafo oficial" da zawiya de Safi, a captação desses materiais contribuiu, inclusive, para a manutenção e o compartilhamento de um acervo sobre a dinâmica religiosa vivenciada no país em parceria com alguns interlocutores interessados em refletir sobre as mudanças em curso do 
"Islã marroquino".

O conjunto desses apontamentos visa a ampliação do debate sobre as condições dispostas nos trabalhos de campos do exterior por parte dos antropólogos. Esses elementos podem adquirir determinadas peculiaridades no fazer etnográfico e, não menos importante, na estruturação dos produtos acadêmicos, tais como a dissertação e a tese. E como se sabe, é partir deles que a tão esperada internacionalização da antropologia pode ser imaginada. Tão logo o pesquisador avance em suas etapas profissionais, espera-se dele que essa produção acadêmica, ligada aos primeiros anos de estudos, se transforme, na medida do possível, em livros, capítulos e artigos. São esses objetos que permitem, por assim dizer, uma mediação com outros contextos de produção acadêmica (países do Norte ou Sul Global) e os diálogos com distintas tradições antropológicas.

Muito passos são necessários na construção dessa internacionalização por parte da antropologia. O meu objetivo aqui foi apenas indicar algumas problemáticas emergentes na formação dos pesquisadores do que realmente determinar quais consequências elas possuiriam visando projetos mais ambiciosos. Mesmo assim, cabe salientar que a discussão não é se a antropologia brasileira está se internacionalizando ou não, mas sim reconhecer que são "[...] os docentes, alunos e pesquisadores que, como indivíduos, inserem-se em redes mais ou menos extensas e com uma variedade de conteúdos" (TRAJANO FILHO; MARTINS, 2004, p. 35). De fato, “[...] devemos nos precaver contra a ideia de que o mero deslocamento rumo além-mar significa uma internacionalização da antropologia brasileira" (TRAJANO FILHO apud FRY, 2004, p. 227). Porém, se toda travessia não está imune de percalços a serem superados, a possibilidade de considerar as três problemáticas indicadas com base nas experiências no Marrocos podem atenuar as dificuldades iniciais na formação de futuros discentes. Assim, os desafios impostos nessas experiências no exterior seriam elementos bons para pensar, sentir e agir antes de serem colocados à prova diante de contextos culturais tão complexos e provocativos.

\section{REFERÊNCIAS}

1. BARTEL, Bruno Ferraz. Criações devocionais no sufismo marroquino: performance e ritual entre os discípulos da tariqa Hamdouchiya. 2019. 246f. Tese (Doutorado em Antropologia). Programa de Pós-Graduação em Antropologia, Universidade Federal Fluminense: Niterói, 2019. 
2. BARTEL, Bruno Ferraz. A dinâmica da baraka no mausoléu de Sidi 'Ali ben Hamdouche, Marrocos. Equatorial, Natal, v. 3, n. 4, p. 11-37, 2016a. Disponível em: https://periodicos.ufrn.br/equatorial/article/view/14906. Acesso em: 22 fev. 2021.

3. BARTEL, Bruno Ferraz. Representação, peregrinação, sacrifício e possessão no culto à Aisha Qandisha. Rio de Janeiro: Autografia, 2016b.

4. BARTEL, Bruno Ferraz. A ambiguidade do sagrado: o culto a Aisha Qandisha na vila de Sidi 'Ali, Marrocos. 2013. 171f. Dissertação (Mestrado em Antropologia). Programa de Pós-Graduação em Antropologia, Universidade Federal Fluminense: Niterói, 2013.

5. BROWN, Kenneth. People of Salé: Tradition and Change in a Moroccan City, 18301930, Cambridge: Harvard University Press, 1976.

6. CLIFFORD, James. Introduction: partial truths. In: CLIFFORD, James; MARCUS, George. (org.). Writing Culture: the Poetics and Politics of Ethnography. Berkeley, Los Angeles, London: University of California Press, 1986. p. 1-26.

7. CORNELL, Vincent J. Realm of the Saint: Power and Authority in Moroccan Sufism. Austin: University of Texas Press, 1998.

8. CRAPANZANO, Vincent. Tuhami: Portrait of a Moroccan. Chicago: University of Chicago Press, 1980.

9. CRAPANZANO, Vincent. The Hamadsha: a Study in Moroccan Ethnopsychiatry. Los Angeles: University of California Press, 1973.

10. DICHTER Thomas. Are We there yet? Geertz, Morocco, and Modernization. The Journal of North African Studies, Londres, v. 14, n. 3-4, p. 543-557, 2009.

11. DWYER, Kevin. Moroccan dialogues. Baltimore: Johns Hopkins University Press, 1982.

12. EICKELMAN, Dale F. Not lost in translation: the influence of Clifford Geertz's work and life on anthropology in Morocco, The Journal of North African Studies, Londres, v. 14, n. 3-4, p. 385-395, 2009.

13. EICKELMAN, Dale F. Knowledge and Power in Morocco: The Education of a Twentieth Century Notable. Princeton: Princeton University Press, 1985.

14. EICKELMAN, Dale F. Moroccan Islam: Tradition and Society in a Pilgrimage Center. Austin; London: University of Texas Press, 1976.

15. FRY, Peter. Internacionalização da disciplina. In: TRAJANO FILHO, Wilson; RIBEIRO, Gustavo Lins. (org.). O campo da antropologia no Brasil. Rio de Janeiro: Contra Capa/ABA, 2004. p. 227-244.

16. GEERTZ, Clifford. Observando o Islã: o desenvolvimento religioso no Marrocos e na Indonésia. Rio de Janeiro: Jorge Zahar, 2004. 
17. GEERTZ, Clifford. Centros, reis e carisma: reflexões sobre o simbolismo do poder. In: GEERTZ, Clifford. O saber local: novos ensaios em antropologia interpretativa. Petrópolis: Vozes, 1997. p. 182-219.

18. GEERTZ, Clifford. After the Fact: Two Countries, Four Decades, One Anthropologist. Cambridge and London: Harvard University Press, 1995.

19. GEERTZ, Clifford. The Religion of Java. Glencoe: The Free Press, 1960.

20. GEERTZ, Hildred et al. Meaning and Order in Moroccan Society: Three Essays in Cultural Analysis. Cambridge: Cambridge University Press, 1979.

21. GELLNER, Ernest. Saints of the Atlas. London: Weidenfeld \& Nicolson, 1969.

22. HAMMOUDI, Abdellah. Master and Disciple: The Cultural Foundations of Moroccan Authoritarianism. Chicago: The University of Chicago Press, 1997.

23. MUNSON JR., Henny. Religion and Power in Morocco. New Haven/London: Yale University Press, 1993.

24. PEIRANO Mariza. Etnografia, ou a teoria vivida. Ponto Urbe, São Paulo, n. 2, 2008. Disponível em: http://journals.openedition.org/pontourbe/1890. Acesso em: 22 fev. 2021.

25. RACHIK, Hassan. Le proche et le lointain: Un siècle d'anthropologie au Maroc. Marseille: Éditions Parenthèses, 2012.

26. ROSEN, Lawrence. Bargaining for Reality: the Construction of Social Relations in a Muslim Community. Chicago and London: The University of Chicago Press, 1984.

27. ROSEN, Lawrence. Muslim-Jewish Relations in a Moroccan City. International Journal of Middle East Studies, Cambridge, v. 3, n. 4, p. 435-449, 1972.

28. RABINOW, Paul. Reflections on Fieldwork in Morocco. Berkeley: University of California Press, 1977.

29. RABINOW, Paul. Symbolic Domination: Cultural Form and Historical Change in Morocco. Chicago: University of Chicago Press, 1975.

30. RIBEIRO, Gustavo Lins. A antropologia brasileira entre políticas neoliberais e a globalização. In: Martins, Carlos Benedito. (org.). Para onde vai a pós-graduação em ciências sociais no Brasil. Bauru: Edusc, 2005. p. 147-167.

31. SCHUCH, Patrice. A dinâmica do campo: temas, tendências e desafios. In: SIMIÃO, Daniel; FELDMAN-BIANCO, Bela. (org.). O campo da antropologia no Brasil: retrospectiva, alcances e desafios. Rio de Janeiro: ABA, 2018. p. 83-103.

32. SLYOMOVICS Susan. Perceptions, not Illustrations, of Sefrou, Morocco: Paul Hyman's Images and the Work of Ethnographic Photography. The Journal of North African Studies, Londres, v. 14, n. 3-4, p. 445-465, 2009. 
33. SIMMEL, George. A natureza sociológica do conflito. In: MORAES FILHO, Evaristo. (org.). Simmel: sociologia. São Paulo: Ática, 1983. p. 122-149.

34. TRAJANO FILHO, Wilson; MARTINS, Carlos Benedito. Introdução. In: TRAJANO FILHO, Wilson; RIBEIRO, Gustavo Lins. (org.). O campo da antropologia no Brasil. Rio de Janeiro: Contra Capa/ABA, 2004. p. 13-38.

Bruno Ferraz Bartel

Doutor em Antropologia pela Universidade Federal Fluminense. Professor do Programa de Pós-Graduação em Antropologia da Universidade Federal do Piauí. Pesquisador do Núcleo de Estudos do Oriente Médio da Universidade Federal Fluminense. ID ORCID: https://orcid. org/0000-0003-4788-0204. E-mail: brunodzk@yahoo.com.br. 